\title{
Análise microbiológica e correlação do ph da água dos bebedouros utilizada para o consumo humano em escolas do município de Alagoa Grande - Paraíba
}

\author{
Microbiological analysis of the water of drinking fountains used for human \\ consumption in schools of the county of Alagoa Grande - Paraiba
}

\author{
Eduardo da Silva Alencar ${ }^{1}$, Rayanna Santana Barros ${ }^{1}$, Roberto Carlos Vieira da Silva Junior ${ }^{2}$, Silvana \\ Câmara Torquato ${ }^{3}$, Wennedy Luiz Silva Marques ${ }^{4 *}$
}

${ }^{1}$ Biomédico pelo Centro Universitário Maurício de Nassau (UNINASSAU); ${ }^{2}$ Biomédico pelo UNINASSAU e Especialista em Microbiologia; ${ }^{3}$ Professora Doutora do UNINASSAU; ${ }^{4}$ Biomédico pelo UNINASSAU e Especialista em Biomedicina Estética

\begin{abstract}
Resumo
Introdução: a análise microbiológica das águas em escolas é de suma importância, visto que crianças em idade escolar são extremamente vulneráveis podendo desenvolver doenças por causa das condições do seu sistema gastrointestinal. Objetivo: avaliar os parâmetros microbiológicos da água de bebedouros destinados ao consumo humano de escolas de Alagoa Grande - PB. Metodologia: foram realizadas avaliações microbiológicas das águas disponíveis nos bebedouros, analisando a potabilidade, bem como as torneiras destes, fazendo levantamento da quantidade de fungos e bactérias encontrados. Os testes foram realizados nos laboratórios do Centro Universitário Maurício de Nassau - Campina Grande. Resultados: 24\% das amostras estudadas apresentaram positividade para o grupo coliforme e termotolerante, portanto, não estão em estado potável para o consumo, e que a manutenção da limpeza dos bebedouros que armazenam a água está deficiente, revelando elevado número de microrganismos e presença de contaminação de todos. Conclusão: as higienizações dos aparelhos, bem como o monitoramento da água consumida nas escolas, são essenciais no controle de doenças que obviamente prejudicam o rendimento escolar dos alunos. As escolas em parcerias com instituições de saúde devem se mobilizar no sentido de capacitar e educar os funcionários que realizam a limpeza dos bebedouros, os alunos e a comunidade que os utilizam, visando a colaboração de todos para melhorar a qualidade da água consumida.
\end{abstract} Palavras-chave: Análise de água. Água potável. Bactéria.

\begin{abstract}
Introduction: the microbiological testing of water available in schools is of paramount importance, as school-age children are extremely vulnerable to developing diseases because of their gastrointestinal system conditions, which underscore the importance of water quality in schools and proper maintenance of the same. The water for consumption is that which is called potable water. The water that do not fit into the standards of potability can lead to pathologies to humans through their consumption. The main pathologies carried by the waters are typhoid fever, cholera, salmonellosis, shigellosis, poliomyelitis, hepatitis $A$, verminoses, amebiasis and giardiasis. The present study aimed to evaluate the microbiological quality of water from drinking fountains intended for human consumption in schools in Alagoa Grande-PB. Metodology: the microbiological analyzes were carried out of the water available in the drinking fountain, analyzing the potability, as well as the taps of these, surveying the amount of fungi and bacteria found. The tests were executed in the laboratories of the Mauricio de Nassau Faculty - Campina Grande and it was found that. Resulting: $24 \%$ of the samples studied presented positivity to the coliform and thermotolerant group, therefore, were not in the potable state for consumption, and that the cleaning of the water fountains is deficient, revealing presence of a high numbers of microorganisms. The fact that the coliform group and thermotolerants were not detected in the other water samples analyzed does not mean that the water is totally safe, since high numbers of fungal and bacterial colonies were found in the nozzles of the drinking fountains. Conclusion: the results showed that the hygiene of the devices, as well as the monitoring of the water consumed in schools, are essential in the control of diseases that obviously impair the students' school performance. The schools in partnerships with health institutions should mobilize to train and educate water cleaners, students, and the community that use them, in order to collaborate with each other to improve the quality of water consumed.

Keywords: Water microbiology. Drinking water. Bacteria.
\end{abstract}

\section{INTRODUÇÃO}

A água é uma das substâncias mais presentes na natureza, sendo ela considerada elemento insubstituível à sobrevivência e existência da vida. Em termos quantitativos, o volume total de água existente na Terra é constante, apontando como um dos grandes problemas do

Correspondente/Corresponding: *Wennedy Luiz Silva Marques - End.: Mariano Rodrigues no16 - Alagoa Grande. CEP: 58388-000 - Paraiba. Tel.: 83 99347-7199. -E-mail: wennedyluiz@hotmail.com século XXI, ressaltando-se que a abundância do elemento líquido causa uma falsa sensação de recurso inesgotável. Entretanto, 97,5\% da água disponível é salgada, sendo inapropriada para o consumo humano. E apenas 2,5\% são de água doce, mas encontra-se inacessível em geleiras ou regiões subterrâneas. Contudo, da parcela de água doce restam apenas $0,007 \%$ da água, podendo ser encontrada em rios e lagos, a qual está passível a exploração e ao uso humano ${ }^{1}$. Segundo a portaria no 2.914 de dezembro de 2011, a água própria para consumo é aquela chamada de 
água potável, ausente de patógenos, cujas características são incolor, inodora e insípida, e que também esteja em concordância com os parâmetros microbiológicos, físicos, químicos e radioativos ${ }^{2}$.

No mundo, 1,1 bilhão de pessoas não possuem água potável disponível. De acordo com a Organização Mundial de Saúde (OMS), estima-se que $80 \%$ das doenças causadas por microrganismos patogênicos são ocasionadas por águas contaminadas $^{3}$.

Fatos históricos comprovam que algumas das mais generalizadas epidemias que já afligiram as populações humanas, tiveram sua origem a partir de água contaminada, é o que acontece com a febre tifoide, cólera, salmonelose, shigelose, poliomielite, hepatite $A$, verminoses, amebíase e giardíase. ${ }^{4}$ Esses organismos são encontrados em diversos locais que se tornam veículos destes até as pessoas, entre eles nos ambientes escolares, estando presentes em banheiros, cantinas e bebedouros, e sendo este último de contato direto por ingestão 4 .

Os bebedouros são aparelhos utilizados para facilitar o acesso das pessoas à água potável, entretanto, é uma grande fonte de contaminação, podendo se apresentar de forma direta por meio da água ou indireta através do contato com o aparelho ${ }^{5}$.

Diante desta perspectiva, percebe-se um problema referente aos bebedouros, uma vez que eles não são bem conservados e, além disso, não apresentarem uma boa alocação, tendo em vista a proximidade da cozinha e dos banheiros, o que pode comprometer a qualidade da água para o consumo, provocando alguns danos à saúde dos alunos.

Sendo assim, este estudo justifica-se pela importância e necessidade de água de boa qualidade (potável) para o consumo dos estudantes, visto que é capaz de veicular grande quantidade de contaminantes físicos, químicos e biológicos, associados às diversas patologias. Nesse contexto, o objetivo desse trabalho constituiu analisar os parâmetros microbiológicos da água dos bebedouros destinados ao consumo humano das escolas do município de Alagoa Grande-PB'

\section{Fundamentação Teórica}

Importância do estudo da água como fonte primária de vida humana

A água é de suma importância para a manutenção da vida no planeta, sendo fruto de combinação desde a sua origem entre os elementos hidrogênio e oxigênio, escrevendo história, criando culturas e hábitos, constituindo a ocupação de territórios, extinguindo e dando vida a espécies, sendo necessária para determinação do futuro das gerações ${ }^{7}$.

Considerada um solvente universal, a água ganha este título pela capacidade de dissolver uma grande quantidade de substâncias (soluto), além de participar de várias funções fisiológicas do nosso organismo, como transporte de mi- nerais e outras substâncias para dentro e fora das células. Nos seres humanos, mais de $60 \%$ do seu peso é constituído por água, tornando-se um elemento dependente para sua sobrevivência. ${ }^{8} \mathrm{~A}$ água é um mineral presente em toda a natureza, destinando-se aos mais diversos fins, como abastecimento público, geração de energia, navegação, suprimento industrial, agricultura, conservação da flora e da fauna, recreação e lazer, entre outras utilidades ${ }^{9}$.

Apesar de todos os esforços para armazenar e diminuir o seu consumo, a água está se tornando, a cada dia, um bem escasso e sua qualidade se deteriora cada vez mais rápido. Em países de terceiro mundo, devido às precárias condições de saneamento e baixa qualidade das águas, as doenças entéricas de veiculação hídrica são culpadas por inúmeros surtos e elevados percentuais de mortalidade infantil, relacionadas à água de consumo humano ${ }^{10}$. A partir disso, a avaliação de sua qualidade microbiológica torna-se algo indispensável.

\section{Doenças de veiculação hídrica}

Inúmeros microrganismos podem ser encontrados nas águas com diversidade bastante significativa, sendo estes, bactérias, fungos, protozoários ou vírus, que podem apresentar-se como naturais do ambiente aquático (autóctones), ou adquiridos pelo solo, ar, despejos domésticos ou industriais (alóctones). Alguns microrganismos patogênicos podem sobreviver na água e infectar seres humanos e animais, a exemplo das bactérias, em especial, do grupo coliforme, as quais vinculadas à água podem transmitir várias doenças. ${ }^{11}$ Portanto, sendo os microrganismos das águas cruciais em vários aspectos, é importante analisá-los e descrevê-los, a fim de que sua distribuição às pessoas possa ser evitada.

Estima-se que, no Brasil, $60 \%$ das internações hospitalares estejam ligadas a precariedade do saneamento básico, diminuindo assim a expectativa de vida da população. As infecções associadas com a qualidade da água ocorrem pela ingestão de água inapropriada para o consumo, pelo contato com a água de deficiente qualidade em zonas de recreio ou ainda ao ingerir alimentos que podem conter vários agentes infecciosos, causadores de patologias ${ }^{12}$.

As principais doenças de veiculação hídrica são febre tifoide, cólera, hepatite infecciosa, gastrenterites, ascaridíase, amebíase e salmoneloses ${ }^{13}$.

A importância das análises de água em ambiente escolar

Avaliar a qualidade da água oferecida nas escolas é de suma importância, uma vez que o ambiente escolar representa uma extensão da casa da criança, ocupando cerca de um terço do seu dia, além de que a criança permanecendo esse tempo na escola ingere bastante água ${ }^{14}$.

Segundo o Programa das Nações Unidas (PNUD) no Relatório de Desenvolvimento Humano (RDH) de 2006 mais de 150 milhões de criança podem ter défice de aprendizagem e sejam perdidos 443 milhões de dias escolares por ano devido a doenças relacionadas à água ${ }^{31}$. 
Crianças na faixa etária de 3 a 12 anos são extremamente vulneráveis a desenvolver doenças por causa das condições do seu sistema gastrointestinal, podendo igualmente ser observado em pessoas adultas que apresentam gastrenterites, anemia, porções do estômago cirurgicamente removidas e mulheres grávidas ${ }^{14}$.

Nota-se que a relação entre água, saúde e educação está extremamente interligada e que podem causar desde a falta de atenção, abandono escolar, ou até a morte, o que se torna de suma importância observar o monitoramento da qualidade da água consumida nas escolas.

Assim, a saúde humana tem, na água consumida, um dos pilares básicos para o alcance de melhor condição e proteção, que pode ser obtido a partir da distribuição de água potável para a população.

\section{Critérios e normas de potabilidade}

A água destinada ao consumo humano deve atender ao padrão de potabilidade, que são as quantidades limites que, com relação aos diversos elementos, podem ser toleradas na água de abastecimento, quantidades definidas geralmente por decretos, regulamentos ou especificações ${ }^{15}$.

Segundo a norma do Ministério da Saúde ${ }^{16}$ presente no artigo $4^{\circ}$, são adotadas as seguintes definições:

I. Água potável-água para consumo humano cujos parâmetros microbiológicos, físicos, químicos e radioativos atendam ao padrão de potabilidade e que não ofereça riscos à saúde;

II. Coliformes termotolerantes - subgrupo das bactérias do grupo coliforme que fermentam a lactose a $44,5 \pm 0,2 \circ \mathrm{C}$ em 24 horas; tendo como principal representante a Escherichia coli, de origem exclusivamente fecal;

III. Escherichia coli-bactéria do grupo coliforme que fermenta a lactose e manitol, com produção de ácido e gás a $44,5 \pm 0,2 \circ \mathrm{C}$ em 24 horas, produzindo a partir do triptofano, oxidase negativa, não hidrolisa a ureia e apresenta atividade das enzimas ß galactosidase e ß-glucoronidase.

Segundo $\mathrm{SAE}^{17}$ a água deve obedecer aos requisitos seguintes: a água para consumo humano e a água tratada no sistema de distribuição (reservatórios e rede) devem conter ausência de coliformes termotolerantes em $100 \mathrm{ml}$ de amostra e a água na saída do tratamento deve conter ausência de coliformes totais em $100 \mathrm{ml}$ de amostra.

A análise da qualidade da água é um fator imprescindível à manutenção da saúde humana, visto que é capaz de veicular grande quantidade de contaminantes físicos, químicos e biológicos, associados às diversas patologias. Nesse sentido, o acompanhamento e monitoramento da água nas escolas justificam-se pela necessidade de água de boa qualidade (potável) para o consumo dos estudantes, evitando assim riscos de contaminação na manipulação da água, bem como a exposição à água contaminada.

\section{METODOLOGIA}

O presente trabalho teve como baseamento metodológico a realização de pesquisa científica quantitativa e qualitativa, utilizando amostras de água dos bebedouros nas escolas do município de Alagoa Grande, Paraíba.

As coletas foram realizadas em 20 escolas, sendo 13 urbanas e 7 em zona rural, todas situadas no município de Alagoa Grande, durante o período de 19 de setembro a 30 de outubro de 2017.

\section{Material e local de análises}

As análises do $\mathrm{pH}$ e microbiológicas das amostras de água e dos bebedouros das escolas em estudo, foram realizadas no Laboratório de Química e Microbiologia, do centro universitário Maurício de Nassau, na cidade de Campina Grande, PB. Para garantia do controle dos padrões de esterilização, os materiais utilizados no laboratório foram previamente autoclavados a $121 \stackrel{\circ}{\circ}$, durante 30 minutos.

\section{Meios de cultura utilizados nos exames microbiológicos da água}

Os meios de cultura são métodos utilizados para cultivo de microrganismos, compostos por nutrientes que favorecem o crescimento e a multiplicação, permitindo a identificação de bactérias e fungos ${ }^{18}$.

Os materiais a serem analisados devem ser adequados a capacidade de crescimento de cada meio, sendo imprescindível para obtenção de resultados satisfatórios a cada amostra ${ }^{19}$.

De acordo com Funasa ${ }^{20}$ as análises de água necessitam de técnicas específicas para detecção e identificação de microrganismos, adotadas para classificar o nível de potabilidade das águas destinadas ao consumo humano. Os meios de cultura padronizados para análise de águas são de estado físico, líquidos (caldos) e sólidos (ágar). Para realização das análises das águas e dos bebedouros das escolas de Alagoa Grande, PB, foram utilizados os meios de cultura líquidos Caldo Lactosado, Caldo Lactosado Verde Brilhante Bile a 2\% e Caldo EC, e sólidos os ágares Trypticase soy agar (TSA), Nutriente e Eosin methilene blue (EMB).

Os meios líquidos utilizados na pesquisa seguiram as práticas de preparação do Manual Prático de Análise de Água - FUNASA ${ }^{20}$ enquanto os meios sólidos foram preparados conforme Procedimento Operacional Padrão (POP) vigente no laboratório de microbiologia da Faculdade Maurício de Nassau - Campina Grande, PB.

\section{Procedimento da coleta, acondicionamento e transporte das amostras coletadas}

Todas as amostras de água foram coletadas após higienização da saída da água com álcool $70 \%$, com escoamento entre um a dois minutos da água retirada no bebedouro e armazenadas em frascos de vidros estéreis, com volume de $250 \mathrm{~mL}$. Destes, $150 \mathrm{~mL}$ destinados a avaliação de PH. As amostras cloradas tiveram o cloro neutralizado imedia- 
tamente após sua coleta adicionando-se $0,1 \mathrm{~mL}$ de solução de tiossulfato de sódio a $10 \%$, para cada $100 \mathrm{~mL}$ de amostra coletada para análise bacteriológica. ${ }^{21} \mathrm{As}$ amostras separadas para avaliação de $\mathrm{PH}$ não tiverem adição de tiossulfato de sódio, para evitar qualquer alteração. Após a coleta, as amostras foram etiquetadas com a numeração correspondente a sequência de escolas e foram preenchidas fichas de identificação, contendo o local da coleta, data, horário, tipo da amostra (especificando a fonte da água) e local de retirada, encontrada nos apêndices. Logo após, foram envoltas em papel alumínio e acondicionadas em caixas isotérmicas, refrigeradas com temperatura em torno de 4 은 C. Após a coleta, as amostras foram encaminhadas para o laboratório de microbiologia do centro universitário Maurício de Nassau de Campina Grande, e analisadas dentro de, no máximo, 3 horas após a coleta.

Para análise da superfície das torneiras em estudo, foram utilizados swabs estéreis e tubos de Pasteur, contento solução salina a $0,9 \%$. Com o swab, fez-se um esfregaço na parte interior de cada torneira e na saída da água. Em seguida, a coleta foi transferida para os tubos de Pasteur, que foram fechados, etiquetados, envoltos em papel alumínio e acondicionados em caixas isotérmicas, refrigeradas com temperatura em torno de 4 ㅇ $\mathrm{C}$ e encaminhadas para o laboratório de microbiologia do centro universitário Maurício de Nassau de Campina Grande.

\section{Análise dos dados}

A pesquisa foi dividida em duas etapas, onde a primeira constou em observar a

higiene e as condições de tratamento dos bebedouros que armazenavam as águas recebidas pelos alunos, observando a presença de bactérias e fungos, e a segunda etapa constou em analisar o grau de potabilidade dessas águas, de acordo com o que estabelece o Ministério da Saúde.

Para verificação do crescimento e contagem das unidades formadoras de colônias de bactérias presentes na superfície das torneiras dos bebedouros em estudo, utilizou-se o Ágar Nutriente, trypticase soy ágar (TSA) e ágar Eosin methilene blue (EMB), semeados com swab em placa de Petri, em torno da chama do bico de Bunsen e incubados de 35 a $37^{\circ} \mathrm{C}$ por 24 a 48 horas. No final do período de incubação, foi realizada a contagem das colônias, com o auxílio de um contador de colônias.

$\mathrm{O} \mathrm{pH}$ foi determinado por potenciometria em eletrodo de vidro, utilizando-se um phmetro de bancada, modelo P1000 da marca PHOX. O medidor de pH foi calibrado com solução tampão de pH 4,0 e 7,0, segundo técnica da A.O.A.C. (2005). $O$ aparelho foi ligado, permanecendo em aquecimento durante 20 minutos, em seguida, eletrodo foi lavado com água destilada e enxuto com papel macio, conforme orientação do fabricante. A determinação do pH é um parâmetro importante, pois indica a acidez ou basicidade das soluções, no caso da pesquisa, a água ${ }^{22}$.

As amostras de água coletadas nos bebedouros das escolas foram caracterizadas quanto à presença de coli- formes a 35 ㅇ $\mathrm{C}$ e termotolerantes. Para essa avaliação, utilizou-se a técnica do número mais provável (NMP), também conhecido como método de tubos múltiplos ${ }^{21}$.

O teste presuntivo avalia a presença de microrganismos fermentadores de lactose, especialmente os grupos coliformes. $O$ teste se baseia na utilização de meio de cultura rico em nutrientes, que facilita o rápido crescimento dos microrganismos. ${ }^{21}$

Na primeira etapa, realizou-se a determinação da presença ou ausência de coliformes a 35C. Foram necessários cinco tubos contendo $10 \mathrm{ml}$ de Caldo Lactosado de concentração simples, onde recebeu amostras contendo $10 \mathrm{ml}$ da água em estudo (diluição 1:1), com tubos de Durham invertidos, os quais foram posteriormente incubados de 35 a $37^{\circ} \mathrm{C}$ por 24 a 48 horas. Transcorrido este tempo, fez-se a leitura dos tubos, onde os que apresentaram formação de gás e turbidez admitiu-se positividade.

Para o teste confirmatório, utilizou-se o Caldo Lactosado Verde Brilhante Bile a $2 \%$, que contém dois inibidores (Bile e Verde Brilhante) para o crescimento da microflora acompanhante, especialmente bactérias gram-positivas, e a lactose, como único carboidrato. Assim, a produção de gás nos tubos e turbidez do meio, nas condições do teste, indica que houve desenvolvimento de bactérias gram-negativas que fermentaram lactose, características do grupo coliforme, sendo observada a produção de gás no interior dos tubos de fermentação (tubos de Durham) e turbidez. ${ }^{22}$ Os tubos que apresentaram formação de gás e/ou turbidez no Caldo Lactosado de concentração simples, foram transferidas pequenas amostras, com alça de transferência estéreis e descartáveis e semeadas em tubos, contendo $10 \mathrm{~mL}$ de Caldo Lactosado Verde Brilhante Bile a $2 \%$ contendo tubos de Durham invertidos para o crescimento de coliformes a 35으.

$O$ teste conformativo para a presença de coliformes termotolerantes foi feito simultaneamente com o teste com Caldo Lactosado Verde Brilhante Bile a 2\%, utilizando-se o Caldo EC, específico para coliformes termotolerantes - Escherichia coli ${ }^{21}$. Os tubos positivos para Caldo Lactosado de concentração simples, tiveram pequenas amostras transferidas com alça de transferência estéreis e descartáveis e semeadas em tubos contendo $10 \mathrm{~mL}$ do Caldo EC, deixados em bando de água em temperatura ambiente por 30 minutos e logo depois incubado em banho-maria de $44,5 \pm 0,2 \circ$ durante $24 \pm 2$ horas. Transcorrido este tempo, fez-se a leitura. A positividade do teste foi observada pela produção de gás no interior dos tubos de Durham e turbidez. Aqueles tubos que turvaram o meio (formação de ácido) e produziram bolhas dentro do tubo de Durham (CO2) foram considerados positivos para coliformes termotolerantes. Qualquer outra opção é interpretada como negativo. A qualificação das amostras foi realizada pela tabela de número mais provável (NMP) - Funasa.

Finalizadas as análises, foi encaminhado às escolas o laudo técnico, acompanhado de folhetos explicativos sobre coliformes e sua relação com a transmissão de 
doenças veiculadas através da água, e de como realizar a desinfecção periódica das caixas d'água, bem como a higienização adequada dos bebedouros.

\section{Análise estatística}

O conjunto de dados analisados advém de 21 amostras de água coletadas em 20 , onde os resultados obtidos foram analisados através de uma análise estatística básica, os dados foram tabulados em planilhas eletrônicas do Microsoft Excel 2010 para geração de gráficos e tabelas.

\section{Aspectos éticos}

O presente trabalho não teve contato direto com pessoas, o que descarta a possibilidade de submissão ao comitê de ética em Pesquisa de acordo com a Resolução 466/12 do Conselho Nacional de Saúde (CNS), porém todos os preceitos éticos estabelecidos serão respeitados no que se refere à zelar pela legitimidade das informações, privacidade e sigilo das informações, quando necessárias, tornando os resultados desta pesquisa públicos.

\section{RESULTADOS}

Para realização da pesquisa, utilizou-se separação em duas etapas, considerando primeiro a potabilidade das águas, sendo analisado o total de 20 escolas e destas, 21 bebedouros, onde em cada escola o número de amostras de água variou de 1 a 2 unidades, sendo consideradas as fontes de retirada da água (Poço artesiano, rede de abastecimento, etc.), classificando a potabilidade da água distribuída, e depois averiguando a presença de microrganismos, onde do total de 20 escolas analisadas, foram coletadas amostras com swabs de 23 bebedouros, onde variou o número entre 1 e 2 , em cada escola, considerando o número de bebedouros disponíveis aos alunos.

Avaliação de potabilidade da água dos bebedouros

Quadro 1 - Presença e ausência de coliformes totais e termotolerantes realizada em amostras de água obtida em 20 escolas da rede pública e privada de ensino.

NÚMERO MAIS PROVÁVEL (NMP)

\begin{tabular}{|c|c|c|c|c|c|c|c|}
\hline AMOSTRAS & $\begin{array}{c}0 \\
(<2,2)\end{array}$ & $\begin{array}{c}1 \\
(2,2)\end{array}$ & $\begin{array}{c}2 \\
(5,1)\end{array}$ & $\begin{array}{c}3 \\
(9,2) \\
\end{array}$ & $\begin{array}{c}4 \\
(16,0) \\
\end{array}$ & $\begin{array}{c}5 \\
(>16,0)\end{array}$ & RESULTADO FINAL \\
\hline 01 & NEG*** & & & & & & ÁGUA POTÁVEL \\
\hline 02 & NEG*** & & & & & & ÁGUA POTÁVEL \\
\hline 03 & NEG*** & & & & & & ÁGUA POTÁVEL \\
\hline 04 & NEG*** & & & & & & ÁGUA POTÁVEL \\
\hline 05 & NEG $* * *$ & & & & & & ÁGUA POTÁVEL \\
\hline 06 a & & POS** & & & & & NÃO POTÁVEL \\
\hline $06 \mathrm{~b}$ & & & & & & POS*** & NÃO POTÁVEL \\
\hline 07 & NEG*** & & & & & & ÁGUA POTÁVEL \\
\hline 08 & NEG*** & & & & & & ÁGUA POTÁVEL \\
\hline 09 & NEG*** & & & & & & ÁGUA POTÁVEL \\
\hline 10 & NEG*** & & & & & & ÁGUA POTÁVEL \\
\hline 11 & & POS*** & & & & & NÃO POTÁVEL \\
\hline 12 & NEG*** & & & & & & ÁGUA POTÁVEL \\
\hline 13 & & & & & & POS*** & NÃO POTÁVEL \\
\hline 14 & NEG*** & & & & & & ÁGUA POTÁVEL \\
\hline 15 & NEG*** & & & & & & ÁGUA POTÁVEL \\
\hline 16 & NEG*** & & & & & & ÁGUA POTÁVEL \\
\hline 17 & NEG*** & & & & & & ÁGUA POTÁVEL \\
\hline 18 & NEG*** & & & & & & ÁGUA POTÁVEL \\
\hline 19 & NEG*** & & & & & & ÁGUA POTÁVEL \\
\hline 20 & & & & & & POS*** & NÃo POTÁVEL \\
\hline TOTAL: 21 & 16 & 2 & & & & 3 & $\begin{array}{l}16 \mathrm{AP} \\
5 \mathrm{NP} \\
\end{array}$ \\
\hline $\begin{array}{l}\text { PORCENTAGEM: } \\
100 \%\end{array}$ & $76 \%$ & $10 \%$ & & & & $14 \%$ & \begin{tabular}{|l|}
$76 \%$ AP \\
$24 \%$ NP
\end{tabular} \\
\hline
\end{tabular}

*Positivo para Caldo Lactosado

**Positivo para Caldo Lactosado e Caldo Lactosado Verde Brilhante Bile a $2 \%$

***Positivo para Caldo Lactosado, Caldo Lactosado Verde Brilhante Bile a $2 \%$ e Caldo EC

Fonte: Dados da pesquisa (2017)

Para a confirmação de coliformes termotolerantes, foi utilizado como meio seletivo o Caldo EC, no qual se pôde constatar que houve presença de coliformes termotolerantes apenas nas amostras $6 \mathrm{~b}, 11,13$ e 20 (quadro 1). 
Figura 1 - Turvação das amostras em caldo Lactosado de concentração simples, Caldo EC e Caldo Lactosado verde Brilhante Bile a $2 \%$ respectivamente.

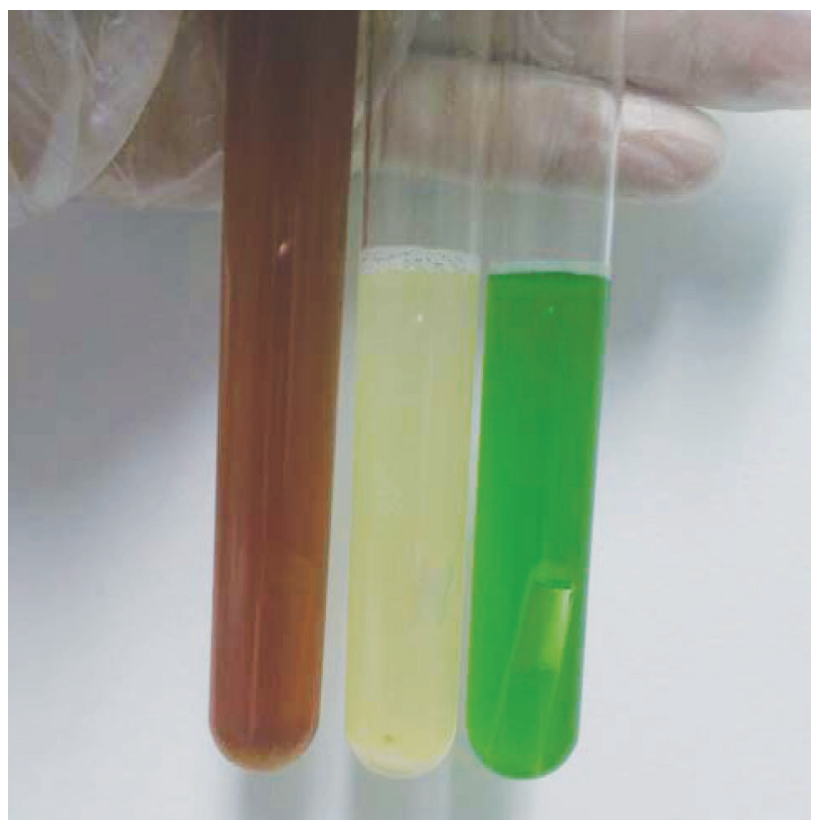

Fonte: Arquivo próprio (2017)

Na Figura 1, representam-se os tubos de uma amostra positiva nos três meios de caldo. De acordo com o quadro $1,24 \%$ das escolas analisadas apresentaram turvação dos tubos com caldos em estudo, resultando numa água não potável do ponto de vista bacteriológico, segundo a legislação vigente, devido à presença de coliformes totais e/ou coliformes termotolerantes.

\section{Análise microbiológica dos bebedouros}

Após o semeio com o swab das amostras das torneiras dos bebedouros das escolas em estudo, observou-se um bom crescimento de colônias bacterianas e fúngicas em meios de culturas não seletivos, TSA e Nutriente (Figuras 2 e 3$)$.

Figura 2 - Amostra A13 em meio TSA. Figura 3 - Amostra A13 em meio Nutriente.
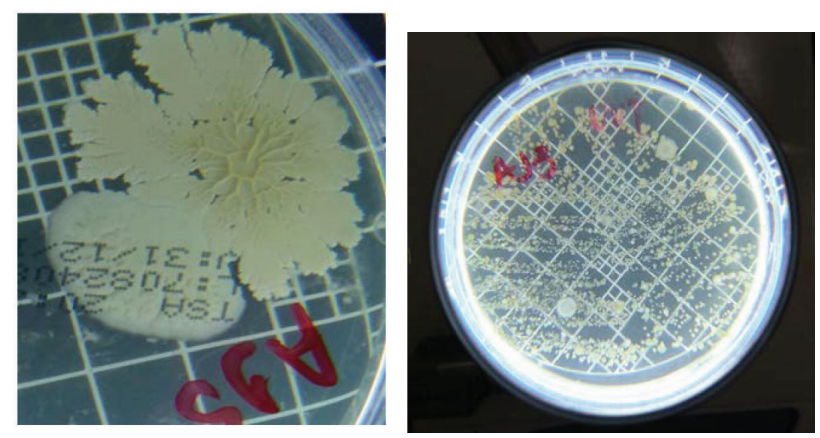

Fonte: Arquivo próprio (2017)
Figura 4-Amostras em meio TSA.

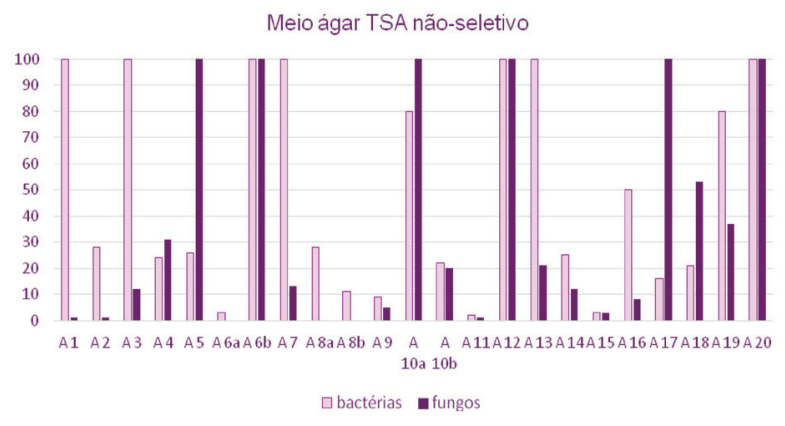

Fonte: Dados da pesquisa (2017)

Figura 5 - Amostras em meio Nutriente

Meio Nutriente não-seletivo

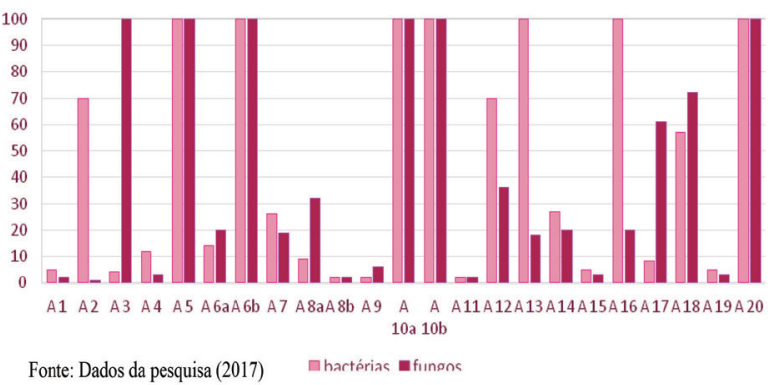

Fonte: Dados da pesquisa (2017)

As amostras em ágar foram analisadas macroscopicamente com o auxílio de um contador de colônias, cujos resultados alcançaram aproximadamente um total por meio estudado de 1.107UFC/g para bactérias e 804UFC/g para fungos no meio TSA (figura 4). No meio Nutriente, o resultado foi aproximado, porém menor em ambas as categorias, onde se totalizaram 1.098UFC/g em bactérias e 760UFC/g em fungos (figura 5). Vale salientar que nas amostras $6 a$, 8a e $8 b$ não foram observados crescimento de unidades formadoras de colônias fúngicas no meio TSA, ao contrário do ágar Nutriente que teve crescimento em todas as amostras.

Figura 6 - Comparativo dos meios TSA e Nutriente.

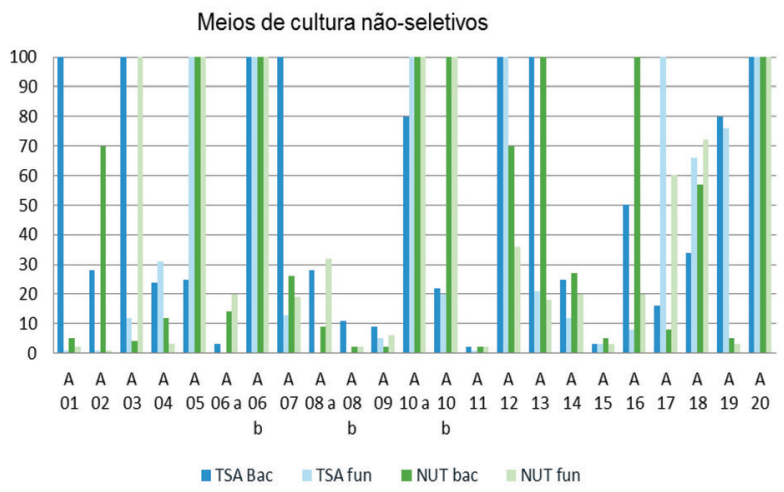

Fonte: Dados da pesquisa (2017) 
Os meios TSA e Nutriente são facilitadores de cultivo de microrganismos, porém por conterem nutrientes diferentes na composição, pôde-se observar que o crescimento foi variado quanto às formas e números de crescimento de bactérias e fungos, fato explicado pela diversidade de exigência dos microrganismos encontrados nas amostras (figura 6).

Figura 7 - Amostras em meio EMB.

\section{MEIO EMB}

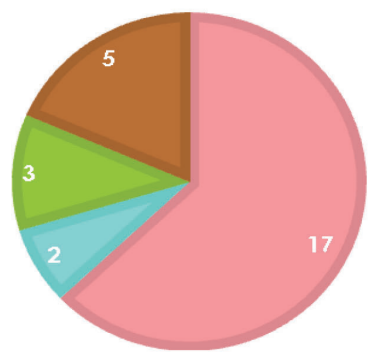

- Escherichia coli

- Klebsiella spp.

Enterobacterspp.

- Negativo

Fonte: Dados da pesquisa (2017)

A análise microbiológica dos bebedouros semeada em placas de Petri contendo o meio EMB, realizada neste estudo, revelou a presença de contaminação nos bocais de todos os bebedouros avaliados. Como evidência a figura 7 , grande maioria das amostras apresentaram contaminação pela bactéria Escherichia coli (17 amostras), 3 apresentaram contaminação por Enterobacter spp., e 2 amostras apresentaram Klebsiella spp., o que demonstra falha na higienização e inadequada limpeza dos aparelhos. Apenas 5 das 21 amostras tiveram crescimento negativo no meio EMB. Estudos que façam avaliação da parte externa do bebedouro não são encontrados na literatura.

\section{Correlação do $\mathrm{pH}$ com as amostras positivas}

Figura 8 - Determinação do $\mathrm{pH}$ das amostras de água nas escolas em estudo.

\section{pH}

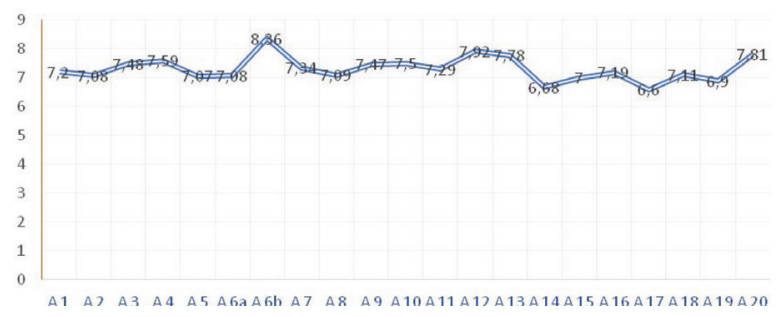

Fonte: Dados da pesquisa (2017)
A figura 8 apresenta os resultados do $\mathrm{pH}$ das amostras de água encontrados, onde pôde-se verificar que todos os resultados obtidos tinham valores de $\mathrm{pH}$ viáveis para o consumo humano.

\section{DISCUSSÃO}

Um recurso essencial para a sobrevivência e desenvolvimento de qualquer forma e vida é a água ${ }^{23}$. Por isso, avaliar a potabilidade da água consumida pelos estudantes deve ser de suma importância, visto que é um meio de fácil contaminação e de contato direto com os mesmos.

Ao se observar os resultados referentes à prova presuntiva e confirmatória de coliformes totais (quadro 1), verificou-se a presença de coliformes totais nas amostras, $6 a, 6 b, 11,13$ e 20 . No restante das amostras, não se detectou presença de coliformes totais. Em análise semeIhante, Zulpo et al..$^{24}$ avaliaram a qualidade microbiológica da água de 47 bebedouros da Universidade Estadual do Centro-Oeste, revelando que $8,5 \%$ das amostras apresentaram positividade para coliformes totais.

Segundo Casali, 252.350 pessoas estão consumindo água fora dos padrões de potabilidade exigidos pelo Ministério da Saúde..$^{26} \mathrm{Em}$ seu estudo sobre a qualidade da água para o consumo humano, ofertada em escolas e comunidades rurais da região central do Rio Grande do Sul, foi encontrado a presença de coliformes totais nas águas de 21 dos 34 pontos monitorados em pelo menos uma das três coletas realizadas.

Na pesquisa de Lima $^{27}$ sobre qualidade da água em ambiente escolar, das dezesseis escolas analisadas, três apresentaram contaminação por coliformes termotolerantes, ou seja, é indício de que houve contaminação fecal recente e isso é um fator preocupante. Uma vez que no ambiente escolar encontram-se muitas crianças com seu sistema imune ainda não completamente desenvolvido, esse tipo de contaminação pode causar sérios danos à saúde de vários alunos.

A simples presença de coliformes totais numa amostra de água potável é suficiente para reprovação da mesma, sem a necessidade de que se obtenha positividade na pesquisa de coliformes termotolerantes.

O número de escolas que tiveram suas águas reprovadas foi consideravelmente alto, visto que se necessita de controle, 5 amostras das 21 estudadas apresentaram-se positivas nos caldos, representando riscos para os alunos que as consomem. Este alto índice de não potabilidade demonstra, na maioria dos casos, desconhecimento e, em outros, negligência na manutenção da escola. Em ambas as situações, comprova-se desinformação relativa aos problemas acarretados pelo consumo de uma água fora dos parâmetros normais exigidos pelas portarias do Ministério da Saúde, que tratam do assunto.

Ao realizar a análise microbiológica das amostras, foi observado que a maior parte dos bebedouros se localizava próximo aos banheiros e apresentava falta de higiene, estados de ferrugem e sujeiras visíveis na parte interna 
do bocal. Um trabalho realizado por Araújo, Baraúna e Meneses ${ }^{28}$ também detectou a presença de ferrugem e outras impurezas nos bebedouros de escolas públicas em Boa Vista (RR). Conforme o autor, os aparelhos encontravam-se, em mau estado de conservação. De acordo com a portaria do Centro de Vigilância Sanitária (CVS-6/99), a melhor forma de evitar a proliferação dessas impurezas é a manutenção semestral e a limpeza semanal ou de acordo com a necessidade, seguindo a regulamentação e os procedimentos de higiene para este tipo de superfície.

$\mathrm{O}$ pH é um padrão de potabilidade, devendo as águas para abastecimento público apresentar valores entre 6,0 e 9,5, de acordo com a Portaria 2.914/11 do Ministério da Saúde. SEMAE, ${ }^{29}$ ressalta que o $\mathrm{pH}$ influi nos processos de potabilização e desinfecção da água, sendo característica importante das águas de abastecimento, visto que interfere na coagulação química, na desinfeç̧ão, no amolecimento de água e no controle da corrosão. $O$ $\mathrm{pH}$ baixo tem potencial corrosivo em tubulações e peças das redes de abastecimento de água e quando elevado possibilita as incrustações. Ressalta ainda que os valores menores que 6,0 do $\mathrm{pH}$ indicam a presença de efluentes industriais, e quando, acima de 9,0, está associado à proliferação de algas.

Como se observou na figura $8, \mathrm{opH}$ das amostras encontradas variou entre 7,2 a 7,8 o que de acordo com a Portaria 2.914/11 do Ministério da Saúde, quanto o pH a água estaria apta para o consumo humano, porém as amostras que apresentaram positividade nos caldos de análise bacteriológica obtiveram maiores valores de $\mathrm{pH}$.

Segundo Schaechter, Engleberg e Barry, ${ }^{30}$ os microrganismos têm valores de $\mathrm{pH}$ ótimo e máximo para sua multiplicação. Verifica-se que $\mathrm{pH}$ em torno da neutralidade $(6,5-7,5)$ é o mais favorável para a maioria dos microrganismos em relação à crescimento e resistência.

\section{CONCLUSÃO}

O estudo evidenciou um índice relativamente alto de coliformes totais e termotolerantes nas amostras de águas coletadas em escolas do município de Alagoa Grande, PB. Ressalta-se que três das cinco amostras que foram positivas são de zona rural, isto indica que há negligência na manutenção das águas e bebedouros, havendo a necessidade de uma fiscalização mais efetiva por parte das instituições de vigilância sanitária, tendo em vista o grande acesso dos alunos aos bebedouros, tornando-se grandes fontes de contaminação de doenças gastrointestinais, como parasitoses e infecções intestinais.

O fato do grupo coliforme e termotolerantes não terem sido detectados nas outras amostras de água analisadas, não significa que a água está totalmente segura, uma vez que foram encontrados elevados números de colônias fúngicas e bacterianas nos bicos dos bebedouros. Acredita-se que a contaminação pode estar ligada a falta de higiene por parte dos usuários, bem como a falta de limpeza adequada e periódica.
Com relação ao $\mathrm{pH}$, todos os valores encontrados estão dentro dos parâmetros exigidos sendo viáveis ao consumo humano.

\section{REFERÊNCIAS}

1. VENDRAMEL, E.; KÖHLER, V. B. A história do abastecimento de água em Maringá, Estado do Paraná. Acta sci., Maringá, v. 24, n. 1, p. 253-260, 2002.

2. BRASIL. Ministério da Saúde. Secretaria de Vigilância Sanitária. Portaria no. 2914, de 12 de dezembro de 2011. Diário Oficial [da] União, Brasília, 2011.

3. COELHO, D. A. et al. Avaliação da qualidade microbiológica de águas minerais comercializadas em supermercados da cidade de Alfenas, MG. Hig. Aliment., São Paulo, v. 21, n. 151, p. 88-92, 2007.

4. RODRIGUES, M. E. et al. Avaliação da percepção ambiental sobre saneamento e recursos hídricos da população do bairro universitário. SEMINÁRIO INTERNACIONAL DE CIÊNCIA, TECNOLOGIA E AMBIENTE, 1., 2009, Paraná.Anais...Paraná:UNIOESTE, 2009. p. 1-11.

5. ARAÚJO, T. M. et al. Análise bacteriológica da água consumida em escolas públicas na capital de Boa Vista-Rr. In: REUNIÃO ANUAL DA SBPC, 62., Natal. Natal: Universidade Federal do Rio Grande do Norte, 2014.

6. CONAMA. Resolução no 274 , de 29 de novembro de 2000 . Legislação para a classificação dos corpos de água. Diário Oficial [da] República Federativa do Brasil, Brasília, DF, 07 de maio. 2005.

7. BACCI, D. de L. C.; PATACA, E. M. Educação para a água. Estud. Av., São Paulo, v. 22, n. 63, p. 211-226, 2008. Disponível em: http://www.scielo.br/scielo.php?script=sci_arttext\&pid $=$ =010340142008000200014\& Ing=pt\&nrm=isso. Acesso em: 05 abr. 2017.

8. BRAGA, B. Introdução à engenharia ambiental. 2 ed. São Paulo: Person Prentice Hall, 2005.

9. IGAM. Gestão das Águas. 2011. Disponível em: <http://www.igam. mg.gov.br/gestao-das-aguas>. Acesso em: 06 abr. 2017.

10. LESER, W. S. et al. Elementos de epidemiologia geral. Cad. Saúde Pública, Rio de Janeiro, v. 1, n. 2, p. 271-272, 1985.

11. PÁDUA, H. Portal bonito. Água e a presença de microrganismos. Ago. 2010. Disponível em: <http://www.portalbonito.com.br/colunistas/helcias-de-padua/247/agua-a-presenca-dos-microrganismos>. Acesso em: 12 set. 2017.

12. LARSEN, D. Diagnóstico do saneamento rural através de metodologia participativa. Estudo de caso: bacia contribuinte ao reservatório do rio verde, região metropolitana de Curitiba, PR. 2010. 182 f. Dissertação (Mestrado) - Universidade Federal do Paraná, Curitiba, 2010.

13. TORTORA, G. J.; FUNKE, B. R.; CASE, C. L. Microbiologia. 8 ed. Porto Alegre: Artmed, 2005. p. 1.

14. MOURA, G. J. B. et al. Análise bacteriológica da água em escolas públicas. (nl). 2002. 7 f. Tese (Doutorado) - Universidade Federal de Pernambuco, Recife, 2002.

15. RIGOBELO, E. C. et al. Padrão físico-químico e microbiológico da água de propriedades rurais da região de Dracena. Rev. Acad., Ciênc. Agrár. Ambient., Curitiba, v. 7, n. 2, p. 219-224, 2009.

16. BRASIL. Portaria $n^{\circ} 518$, de 25 de março de 2004. Legislação para águas de consumo humano. Diário Oficial [da] República Federativa do Brasil, Seção 1, Brasília, DF, 26 de mar. 2004. 
17. SISTEMA DE ÀGUA E ESGOTO (SAE). Potabilidade - a qualidade da água que se bebe. 2012. Disponível em: http://www.jurere.com. br/sae/potabilidade.htm. Acesso em: 03 abr. 2017.

18. JESUS, S. J. M. Portal Educação. Meio de cultura: microbiologia clínica. jan. 2015. Disponível em: https://www.portaleducacao. com.br/conteudo/artigos/idiomas/meio-de-cultura-microbiologia-clinica/59094. Acesso em: 23 out. 2017.

19. BRASIL. Agência Nacional de Vigilância Sanitária. Manual de microbiologia clínica para o controle de infecção relacionada à assistência à saúde. Módulo 4: Procedimentos Laboratoriais: da requisição do exame à análise microbiológica e laudo final. Brasília:Anvisa, 2013.

20. BRASIL. Ministério da Saúde. FUNASA. Manual prático de análise de água. 2. ed. Brasília (DF): Assessoria de Comunicação e Educação em Saúde, 2006

21. SILVA, N.; NETO, R. C.; JUNQUEIRA, V. C. A.; SILVEIRA, N. F. A. Contagem de coliformes totais e termotolerantes. Revista Higiene Alimentar, São Paulo, v. 21, n. 154, p.103-105, jul./ago. 2007

22. MACÊDO, J. A. B. Águas e águas. São Paulo: LivrariaVarela, 2001.

23. TUNDISI, J. G. As Árvores e a Conta da Água. Scientific American Brasil, Brasil, 2005.

24. ZULPO, D. L. et al. Avaliação microbiológica da água consumida nos bebedouros da Universidade Estadual do Centro-Oeste, Guarapuava, Paraná, Brasil. Semina Ciênc. Agrar., Londrina, v. 27, n. 1, p. 107-110, 2006.

25. CASALI, C. A. Qualidade da água para consumo humano ofertada em escolas e comunidades rurais da região central do Rio Grande do
Sul. 2008. 173f. Dissertação (Mestrado) - Universidade Federal De Santa Maria, Santa Maria, 2008.

26. BRASIL.Ministério da Saúde. Secretaria de Vigilância em Saúde. Portaria M. S, n. 9 518, de 25 março de 2004. Estabelece os procedimentos e responsabilidades relativos ao controle e vigilância da qualidade de água para consumo humano e seu padrão de potabilidade, e dá outras providências. Brasília: Ministério da Saúde, 2005. (Série E. Legislação Saúde).

27. LIMA, B. J. L. A. Qualidade de água no meio ambiente escolar ponto de partida para educação ambiental. Universidade Federal de Pernambuco. Centro de Ciências Biológicas. Departamento de Antibióticos. Recife, 2009.

28. ARAÚJO, T. M.; BARAÚNA, A. C.; MENESES, C. A. R. Identificação de Escherichia coli em água de bebedouros e nos próprios aparelhos de quatro escolas públicas de Boa Vista - Roraima-Brasil. IN: CONGRESSO DE PESQUISA E INOVAÇÃO DA REDE NORTE NORDESTE DE EDUCAÇÃO TECNOLÓGICA, 4., 2009, Belém. Anais... Belém: CONNEPI, 2009.

29. SEMAE. Serviço Municipal de água e esgoto de São Leopoldino-RS. Relatório da água 2016 - Relatórios anuais de qualidade da água tratada. Disponível em: http://www.semae.rs.gov.br/novo//conteudo_semae. php?menuv=12. Acesso em: 16 out. 2017.

30. SCHAECHTER, M.; ENGLEBERG N. C.; BARRY I. Microbiologia mecanismos das doenças infecciosas. 3 ed. Rio de Janeiro: Guanabara Koogan, 2002.

31. PNUD. Programa das Nações Unidas para o Desenvolvimento. Resumo Relatório do Desenvolvimento Humano 2006: A água para lá da escassez. 2006. 52 p. Disponível em: . Acesso em: 10 Julho. 2020.

Submetido em: 09/10/2018

Aceito em: 21/08/2020 